\title{
AS IDEIAS VOLTARAM AO LUGAR? temporalidades não lineares no neoliberalismo autoritário brasileiro e sua infraestrutura digital
}

\author{
Letícia Cesarino*
}

\begin{abstract}
O artigo aborda como a inflexão populista-autoritária do neoliberalismo global tem ganhado tração no Brasil ao se friccionar com sua densidade histórica pós-colonial, marcada pela disjunção entre ideais liberais, igualitários e universalistas, e uma realidade social desigual e particularista. Volta-se especialmente à convergência infraestrutural entre neoliberalização e plataformização, que, ao consolidar uma temporalidade paradoxal de crise permanente, abre espaço para ressonâncias com "forças e poderes" que também operam de forma não linear, segundo a metafísica da desordem, como os diversos modos de nostalgia, milenarismo e tradicionalismo que acompanham a ascensão da direita radical pelo mundo. Argumento a partir de dois momentos do bolsonarismo: o messianismo populista nas eleições de 2018 e sua rotinização paradoxal enquanto governo parasítico na pandemia da Covid-19, que opera numa temporalidade de exceção. Sugere-se que, diante da deriva iliberal do neoliberalismo contemporâneo, o bolsonarismo lança o Brasil à vanguarda, colocando as ideias "de volta no lugar".
\end{abstract}

Palavras-chave: Neoliberalismo. Plataformização. Brasil. Bolsonarismo. Crise.

\section{INTRODUÇÃO}

Em 1977, o crítico literário Roberto Schwarz (2014) publicou seu conhecido argumento do liberalismo como "ideia fora do lugar" no país escravocrata que era o Brasil do século XIX, com todo seu legado histórico de desigualdades arraigadas, transversais aos domínios econômico, racial, de gênero e de regionalidade. A condição pós-colonial brasileira seria caracterizada por uma disjunção persistente entre uma realidade social desigual e personalista, e uma normatividade política universalista e igualitária (o progresso, a democracia liberal) que está sempre em outro lugar (a Euro-América, o Norte global). ${ }^{1}$ O Brasil

\footnotetext{
* Universidade Federal de Santa Catarina (UFSC). Departamento de Antropologia e Programa de Pós-Graduação em Antropologia Social (PPGAS). Centro de Filosofia e Ciências Humanas (CFH).

Campus Universitário Reitor João David Ferreira Lima Bairro Trindade. Cep: 88040-400. Florianópolis - Santa Catarina - Brasil. leticia.cesarino@ufsc.br https://orcid.org/0000-0001-7360-0320

${ }^{1}$ Schwarz (2014) não utiliza o termo pós-colonial. A leitura de que seu texto avança um tipo de crítica pós-colonial, específica às contradições próprias da história brasileira em que o componente da colonialidade interna sempre foi central (Cesarino, 2017), é minha.
}

parecia, assim, fadado ao destino paradoxal de ser o país de um futuro que nunca chega.

Entretanto, hoje, mesmo esse horizonte de futuro parece se desfazer. Como alguns têm argumentado, os efeitos precarizantes e desestabilizadores de décadas de hegemonia neoliberal vêm universalizando a disjunção notada por Schwarz para os próprios países "centrais" (Comaroff; Comaroff, 2011). A temporalidade linear do progresso que sustentava o paradigma da modernização vem se desestruturando diante do acirramento das contradições da globalização neoliberal, levando consigo a escala hierárquica global baseada em noções de desenvolvimento e subdesenvolvimento que prevaleceu durante boa parte do século XX (Ferguson, 2006). Entre as reverberações dessa reorganização espaço-temporal está a ascensão da chamada pós-verdade e da direita populista pelo globo, a partir de 2008. Antes, vistos como característicos de democracias subdesenvolvidas, notadamente na América Latina, movimentos populistas, inclusive com fortes derivas iliberais ou fascistas (Connolly, 2017), proliferam também em grandes democracias liberais do Norte global. Teorias da conspiração, 
negacionismos e fake news vicejam nos países berço da ciência moderna, notadamente a partir da pandemia da Covid-19 iniciada em 2020.

Este ensaio se alinha com análises que sugerem que a eficácia dos populismos, conspiracionismos, punitivismos e outras gramáticas "iliberais" que alimentam e são alimentadas por movimentos da direita radical, como o bolsonarismo, está na sua capacidade de responder a contradições internas à própria formação neoliberal, ao mesmo tempo em que pressionam pela sua renovação na direção de um viés não democrático ou autoritário (Brown, 2019; Davies, 2021). Essas tendências, que são globais, ganharam tração no contexto brasileiro nos anos que antecederam a chegada ao poder da direita conservadora com Jair Bolsonaro em 2018. Embora o viés das "guerras culturais" acabe ficando em maior evidência (Rocha, 2021), o objetivo da coalizão bolsonarista é desfazer o pacto de 1988 em todo seu espectro do reconhecimento à redistribuição (Fraser, 1991) - esta última manifesta de modo mais explícito na agenda econômica ultraliberal personificada em Paulo Guedes. Considerando a formação neoliberal como mais que apenas uma política econômica, tomamos o caleidoscópio bolsonarista (Kalil et al., 2018) como unido por ressonâncias, menos imediatamente visíveis do que uma suposta separação entre um nível "liberal na economia" e outro "conservador nos costumes" faria parecer స్స్ (Cesarino, 2019).

กิ Em sua análise da aliança neoliberal-conservadora durante os governos Bush, William Connolly (2021) propôs a noção de o” "máquina de ressonância" para pensar aqui$\dot{2}$ lo que une esses diferentes segmentos fora de कि chaves analíticas ancoradas em pressupostos $\overrightarrow{\text { de }}$ "causalidade eficiente ou análise ideológica”. Ele buscou lançar luz, por outro lado, sobre camadas subliminares de "disposições espirituais semelhantes" entre esses grupos: um "ethos", que é "expresso sem ser articulado" e que se propaga por diferentes infraestruturas de mídia. Embora, naquele momento,
Connolly já houvesse identificado o papel das mídias eletrônicas, o deslanche do processo de plataformização da internet só se daria após a crise financeira de 2008 - mesmo marco que outros identificaram como ponto de virada rumo à renovação da convergência neoliberal-autoritária manifesta no trumpismo, Brexit e afins (Brown, 2019; Davies, 2021). Este artigo parte de uma perspectiva que recoloca, nos termos da analítica das ressonâncias de Connolly, o que Gerbaudo (2018) e Waisbord (2018) entenderam como "afinidades eletivas" entre as novas mídias e os populismos e conspiracionismos contemporâneos.

Entre as várias dimensões dessa problemática, destacarei aqui o modo como essa infraestrutura cibernética intervém para acirrar e, ao mesmo tempo, redirecionar um processo anterior, relativo ao modo como o neoliberalismo desloca os sentidos lineares da temporalidade moderno-fordista (Sennett, 1999). A plataformização da internet teria, segundo Chun (2016), intensificado a convergência formal entre infraestrutura de mídia e o neoliberalismo, ambos marcados por uma temporalidade de crise permanente. Em meados dos anos 2000, antropólogos como Jane Guyer (2007) e Jean e John Comaroff $(2000,2004)$ sugeriram que as temporalidades não lineares do neoliberalismo - marcadas por uma "ferradura" que une o imediatismo da experiência e dos eventos, por um lado, e futuros inescrutáveis e intangíveis, por outro - vinham propiciando o afloramento de processos sociais estranhos à normatividade da modernidade liberal. Com efeito, essas tendências viriam, uma década depois, a convergir fortemente na e com a direita alternativa, em derivas populistas, apocalípticas, messiânicas, conspiracionistas, negacionistas etc. É nesse sentido que proponho, aqui, abordar o bolsonarismo a partir de uma releitura da disjunção histórica colocada por Schwarz: não enquanto déficit em relação à temporalidade linear do progresso e da modernidade liberal, mas como realinhamento retrospectivo do substrato sócio-histórico bra- 
sileiro à configuração neoliberal-autoritária emergente globalmente.

Neste artigo, exploro como a máquina de ressonância do bolsonarismo viceja na temporalidade não linear do neoliberalismo, com foco na atual infraestrutura de mídia. Por um lado, há a dimensão messiânica mais evidente, que se mostrou central à eficácia do discurso e estratégia eleitoral bolsonaristas, especialmente após o atentado a faca em setembro de 2018. Por outro, a pandemia da Covid-19 evidenciou uma forma contraditória de governo que se perpetua parasitando o próprio sistema ao qual ele alega se opor (Nobre, 2020), liderado por um soberano que, embora já autorizado pelo "povo", reiteradamente adia a decisão sobre o estado de exceção (Abreu, 2019).

Suspensos num estado paradoxal em que convivem horizonte apocalíptico e sobrevivência cotidiana (Guyer, 2007), muitos segmentos da população brasileira têm experimentado a catastrófica gestão federal da pandemia como plausível. Sugiro que parte dessa plausibilidade possa advir do modo como o bolsonarismo, ao abandonar o horizonte linear do Estado social e planejador (Mirowski, 2019), realinha o presente neoliberal ao legado histórico desigual e contraditório apontado por Schwarz. Em outras palavras, ao sincronizar o déficit liberal-democrático do país à deriva iliberal do neoliberalismo contemporâneo, ele colocaria as ideias "de volta no lugar".

Para desenvolver essa reflexão, a primeira seção retoma brevemente argumentos sobre o "neoliberalismo realmente existente", destacando sua dimensão temporal não linear. Aponto um aspecto pouco trabalhado pela literatura, que diz respeito à base infraestrutural dessas temporalidades nas novas mídias, centrais à eficácia tanto de Bolsonaro como dos demais populistas da direita radical. Na segunda seção, discuto as gramáticas populistas e conspiratórias que proliferaram nas redes sociais bolsonaristas, em dois períodos cruciais. Enquanto a eleição de 2018 ressaltou a dimensão messiânica do bolsonarismo, a pandemia da Covid-19 em 2020 evidenciou seu investimento num estado de exceção permanente e no viés neodarwinista ou spenceriano da atual formação neoliberal.

Concluo sugerindo que a resiliência do bolsonarismo, mesmo em meio à maior crise humanitária da história recente do país, se liga à incapacidade de muitos brasileiros de atribuir responsabilidade pelos efeitos sanitários e econômicos ao governo federal e, mais especificamente, à pessoa do presidente. Enquanto boa parte dessa incapacidade parece advir de uma estratégia comunicacional eficaz em defletir causalidade a partir do ambiente entrópico propiciado pela plataformização, ela também se liga ao processo mais fundamental de deslocamento neoliberal do "social" pela ênfase na responsabilização individual e familiar (Brown, 2019; Dardot; Laval, 2016). No caso brasileiro, essa tendência, que é global, ganha tração a partir de uma densidade histórica local em que particularismos e desigualdades arraigadas, e o abandono dos mais vulneráveis pelo Estado e pelas elites, conformaram uma cultura política que sempre operou em disjunção com a normatividade democrática de base liberal-igualitária - a mesma que se encontra, hoje, em crise por todo o mundo.

\section{TEMPORALIDADES NEOLIBERAIS E SUA BASE MATERIAL}

A análise da crise financeira de 2008 tem dividido opiniões: se caracterizaria um abandono ou uma renovação da hegemonia neoliberal (Plehwe; Slobodian; Mirowski, 2020) - tudo depende de como se entende o termo. A primeira posição faz sentido se entendermos o neoliberalismo como uma agenda de política econômica, cujo desdobramento, especialmente no pós-pandemia, parece se inflexionar no sentido de uma maior flexibilização do receituário da austeridade e do alcance regulatório do Estado, inclusive no caso da indústria tech (Carvalho, 2020). Autores como Peck, Theodore e Brenner 
(2012) alertam, contudo, que o neoliberalismo viceja justamente de forma contraditória, enquanto “modo de regulação parasítico" (p. 274) de outras formas político-econômicas com as quais antagoniza, como o Estado desenvolvimentista e a social-democracia.

Além disso, o neoliberalismo também se adapta ao convergir com outras forças sociais. Se tomarmos o termo no sentido do viés foucaultiano, ele denota uma racionalidade de governo que não apenas extrapola o domínio econômico, como opera pela contaminação e desdiferenciação entre a economia e outras esferas sociais (Brown, 2015; Foucault, 2008). Suas implicações passam a abranger, assim, todo o espectro da vida, desde a construção de subjetividades e moralidades até a conformação de um novo regime epistêmico e espaço-temporal (Comaroff; Comaroff, 2000; Guyer, 2007). Ao mesmo tempo, o próprio neoliberalismo vai mudando na sua articulação recíproca com outras "forças e poderes" (Brown, 2019), ao ponto de alguns cogitarem, atualmente, uma formação pós-neoliberal que recombinaria, de formas novas e híbridas, os polos da soberania e governamentalidade (Davies, 2021), da tecnocracia e do populismo (Bickerton; Acetti, 2021).

Ressaltar o caráter do neoliberalismo como mais que uma política econômica tampouco significa reduzi-lo a um regime simbólico. O próprio Foucault, assim como o marปิ xismo, a cibernética e a antropologia lembram ปิ que não existe subjetividade, epistemologia ou ปิ racionalidade, desvencilhados de uma base ma\&ิ terial. Toda comunicação é material, mesmo a $\rightarrow$ digital, que opera com bits no lugar de átomos ${ }_{\dot{2}}$ (Boyd, 2011). No caso do neoliberalismo conÆî temporâneo, é possível destacar o papel articu$>$ lado de dois processos de desterritorialização, a financeirização e a digitalização, para o avanço transversal da racionalidade neoliberal - na Fi realidade, como esse avanço faz colapsar, ao mesmo tempo em que rearranja, antigas diferenciações historicamente sedimentadas no ocidente moderno, como aquela entre público e privado (Boyd, 2011; Chun, 2016). Esta seção explora as ressonâncias entre neoliberalismo e digitalização a partir de suas convergências infraestruturais, que deslocam a temporalidade linear do progresso prevalente até meados do século XX.

Partimos aqui da ideia de que essas convergências infraestruturais ajudam a conformar - ou seja, a dar forma - à ressonância crescente entre o neoliberalismo e outras forças: punitivistas (Comaroff; Comaroff, 2004; Wacquant, 2009), necropolíticas e racistas (Mbembe, 2018), conservadoras (Brown, 2019), religiosas (Connolly, 2021), soberanistas (Davies, 2021), messiânicas e mágicas (Comaroff; Comaroff, 2000). Essas (re) articulações emergentes, observadas por diferentes autores, não se dão por pressões puramente "externas" ao neoliberalismo, mas são atualizadas a partir de potencialidades inerentes à própria doutrina e prática neoliberais. Desde suas origens, no que se convencionou chamar de Coletivo de Pensamento Neoliberal (Plehwe; Slobodian; Mirowski, 2020), o amplo movimento pela renovação do liberalismo no início do século XX se deu não de forma coesa, mas por meio de fraturas e contradições entre linhas mais ou menos progressistas, intervencionistas, conservadoras ou spencerianas-neodarwinistas (Dardot; Laval, 2016). Essa heterogeneidade interna permite que o neoliberalismo ganhe tração global por meio de fricções (Tsing, 2007) diferenciais com contextos históricos e geográficos os mais diversos, ao mesmo tempo em que mantém, por toda parte, um "ar de família” (Peck; Theodore; Brenner, 2012).

Boa parte da literatura antropológica sobre neoliberalismo tem tratado do modo como ele altera a conformação espaço-temporal que prevaleceu ao longo do período keynesiano-fordista, marcado pela temporalidade do progresso e da modernização, e suas hierarquias globais associadas. Com o fim da Guerra Fria, a escala linear e rígida do sub/desenvolvimento deu lugar ao espectro mais fluido do Norte/ Sul globais, pensado de forma multiescalar, enquanto fraturas inclusive internas ao mun- 
do "desenvolvido": haveria um Norte no Sul, e um Sul no Norte (Ferguson, 2006). Assim, fenômenos anteriormente associados a realidades terceiro-mundistas em vias de superação, como o trabalho informal, o (re)encantamento do mundo ou o próprio populismo passam a ser identificados também no antigo Primeiro Mundo (Comaroff; Comaroff, 2011).

Jane Guyer (2007) propôs a noção de "tempo pontuado" (punctuated time) para caracterizar essas mudanças. Segundo a antropóloga, o neoliberalismo desloca a imaginação modernista de um futuro próspero potencialmente alcançável por todos - o que Mark Fisher (2020) chamou de cancelamento do futuro -, deixando apenas o tempo presente, imediato, por um lado, e um futuro que é distante e imprevisível, por outro. O presente se torna assim uma série de eventos a que os indivíduos devem responder de forma mais ou menos ad hoc - o que converge com o diagnóstico de Chun (2016) sobre o espaço-tempo da internet plataformizada. A ênfase na experiência individual (do your own research) é assim complementada pela confiança quase cega em um "plano" maquinado por forças invisíveis e em última instância inescrutáveis (trust the plan) - sejam elas de ordem religiosa ou espiritual, ou de ordem secular, como a própria mística da mão invisível do mercado (Cesarino; Silva, [2021?]).

Guyer nota que as implicações cognitivas desse tipo de temporalidade já estavam previstas na formulação original da doutrina neoliberal por Hayek. Esta, como elaborou Mirowski (2019), partia do pressuposto da incapacidade cognitiva de sujeitos individuais e coletivos, e da superioridade epistêmica do livre-mercado como processador de informação. Guyer argumenta que essa suposição de ininteligibilidade é a base para a eliminação do horizonte temporal "médio" que conformava o viés linear planejador característico do período keynesiano-fordista (e, poderíamos acrescentar, o "social" durkheimiano que protagonizou a institucionalização das ciências sociais no início do século XX, inclusive enquanto base para políticas públicas). Nesse sentido, a temporalidade neoliberal encontraria ressonâncias menos com a "flecha" da modernização do que com espaços-tempo não lineares, como no dispensacionalismo cristão (Connolly, 2021) e nas doutrinas tradicionalistas que caracterizam a direita alternativa nos EUA, no Brasil e alhures (Teitelbaum, 2020).

O casal de antropólogos sul-africanos Jean e John Comaroff (2000) capturou bem essa inflexão espaço-temporal e seus efeitos socioepistêmicos na metáfora do neoliberalismo enquanto "segunda vinda", milenarista, do capitalismo, após o interregno keynesiano-fordista do pós-guerra. Como na segunda vinda de Cristo, o capitalismo financeirizado intervém desestruturando o horizonte de futuro linear do progresso, dando lugar a temporalidades não lineares que costumamos associar a formações não modernas e epistemologias não científicas: do "capitalismo de cassino" aos discursos messiânicos e apocalípticos (religiosos, mas também seculares, como no Antropoceno) e em teorias da conspiração, como o QAnon; de vigilantismos e punitivismos de toda sorte (como, hoje, os tribunais de internet) a linguagens vitalistas de parasitismo, que podem assumir a forma literal de rumores sobre vampiros, zumbis, traficantes de órgãos, judeus bebedores de sangue humano e afins; de causalidades encantadas e ocultas a oráculos, esquemas-pirâmide e outras manifestações do que, na era da internet plataformizada, veio a se chamar desinformação ou pós-verdade (Cesarino e Silva [2022])

Em sua tese clássica sobre a "doutrina do choque", Naomi Klein (2008) destacou a aceitação de políticas neoliberais pelas populações de países onde elas foram implementadas de forma não democrática em nome de uma reimposição da ordem na esteira de grandes rupturas e crises, como o Chile de Pinochet, o Iraque pós-Guerra do Golfo ou a Louisiana pós-Katrina. Hoje, podemos dizer que a doutrina do choque neoliberal se implementaria 
não (apenas) por catástrofes, golpes de Estado e outros eventos lineares, mas por uma infraestrutura não linear e autossimilar (fractal) que distribui e capilariza a crise por escalas múltiplas, para além da política e da economia pensadas enquanto domínios discretos do real (Cesarino e Silva [2022]). Muitos notaram como a precarização generalizada da vida no neoliberalismo transpõe o estado de crise para a vida cotidiana, com consequências multidimensionais para os indivíduos e famílias (Comaroff; Comaroff, 2004; Guyer, 2007). Fisher (2020) notou, por exemplo, a ressonância entre dinâmicas do capitalismo financeirizado e distúrbios mentais endêmicos, como os ciclos de boom and burst dos mercados e as oscilações bipolares de depressão e euforia que afligem porções cada vez maiores de vidas submetidas ao ritmo do "tempo pontuado" neoliberal.

Está bem estabelecido, notadamente na literatura sobre fascismo (Paxton, 2008; Connolly, 2017), que estados de crise acirram o que Jean e John Comaroff (2004) chamaram de dialética da "produção e redução da desordem”. Durante a ascensão da guerra ao terror nos anos 2000, esses autores explicaram a centralidade (e mistura) crescente da mídia jornalística e da ficção tematizando crime, violência, segurança e ordem nas esferas públicas da África do Sul e alhures como reflexo de inseguranças mais fundamentais acerca da ascensão do Estado securitário neoliberal (Mbembe, ปิ 2018; Wacquant, 2009). A nostalgia por lídei res autoritários e justiceiros (agindo extrajudicialmente, se preciso for) seria assim uma resposta à "metafísica da desordem”, em que ○” a sociedade é entendida como estando "à beira $\dot{2}$ da dissolução". Durante a campanha de 2018, ஓं essas narrativas fundamentais sobre a ordem $\vec{*}$ político-cosmológica foram materializadas em memes nos quais Bolsonaro e Moro apareciam fundidos às figuras de super-heróis, soldados, cruzados medievais ou policiais. Esse gênero de storytelling, alimentado há anos no Brasil e alhures por uma mídia policialesca que foi renovada nas narrativas orgânicas no WhatsApp
(Cesarino, 2020; Junge, 2019), viceja dialeticamente na "conjuração produtiva de um mundo saturado de violência e ambiguidade moral, cuja ameaça apenas eles [as figuras populistas] são capazes de reduzir a uma ordem habitável" (Comaroff; Comaroff, 2004, p. 824).

Estudos mais recentes no campo das novas mídias ajudam a compreender o enraizamento cognitivo dessa metafísica da desordem no quotidiano dos usuários, notadamente pela via pré-representacional da mobilização de afetos, hábitos e atenção (Chun, 2016; Connolly, 2021). Muitos notaram convergências fundamentais entre a infraestrutura digital contemporânea e tendências transversais a fenômenos que costumam andar juntos, como os populismos da direita radical, punitivismos, conspiracionismos e negacionismos (Fielitz; Marcks, 2019; Gerbaudo, 2018; Waisbord, 2018). Mais recentemente, alguns vêm pontuando que essa infraestrutura consiste não apenas na face mais visível e "oficial" da internet, mas também, e principalmente, nas camadas que se formaram "sob o radar" (Abidin, 2021) das plataformas a partir dos seus efeitos antiestruturais - que Gray, Bounegru e Venturini (2020) chamaram, com base na teoria do Unheimlich freudiano, de "estranho-familiar infraestrutural".

Central à dimensão temporal em tela é o modo como a capilarização crescente do ritmo intensivo da economia da atenção junto aos usuários tem contribuído para aprofundar o estado de crise permanente diretamente junto a e a partir dos processos cognitivos humanos. Fielitz e Marcks (2019) ressaltaram a centralidade dessa temporalidade para a proliferação de afetos fascistas, como medo e ressentimento, em sua elaboração recente do que chamaram de "fascismo digital". Leirner (2020) elaborou os notáveis paralelos que fenômenos como populismo e desinformação guardam com a reformulação da teoria e prática militar nas últimas décadas, em direção às guerras de espectro total ou híbridas - que, no Brasil, têm se desdobrado menos em torno de um inimigo externo do que ao longo das linhas históricas 
da colonialidade interna (Cesarino, 2017).

Provavelmente foi Wendy Chun (2016) quem melhor trabalhou as ressonâncias fundamentais entre as infraestruturas cibernéticas e neoliberais, no modo como ambas se sustentam em uma espacialidade de públicos-em-rede articulada com uma temporalidade de crise permanente. As plataformas operam pela interpelação contínua dos usuários por "eventos" aos quais devemos reagir, produzindo uma externalização do nosso fluxo de atenção e consciência que permite o exercício de influência (literalmente, colocação em fluxo) tão fundamental ao seu modelo de negócios. Como a autora destaca, interpeladas numa temporalidade de crise permanente, as camadas cognitivas responsáveis pela formação de hábito e memória incorporada (embodied) tendem a degenerar em adição - o lado obscuro, mas não menos sistêmico, da meta corporativa do "tempo de tela". Aqui, a race to the bottom (corrida para o fundo) neoliberal se transmuta numa luta neocortical pela atenção dos usuários, levando, nos termos de Harris (2017), a uma race to the bottom of the brain stem. ${ }^{2}$ Neoliberalismo e plataformização se sincronizam, assim, ao ritmo da competição spenceriana pela existência, em que perfis on-line e sujeitos off-line precisam fazer cada vez mais apenas para conseguirem seguir existindo enquanto tais: nos termos de Chun, "se atualizarem para continuarem iguais".

Chun nota, ainda, o enraizamento desse espaço-tempo na experiência(ilusória) de desintermediação propiciada pela arquitetura das plataformas. O sistema de peritos prevalente no período keynesiano-fordista - centrado na ciência, mas com a lógica da expertise se estendendo à política partidária, jornalismo profissional, sistema educacional, jurídico-legal etc. (Cesarino, 2021) - é deslocado assim por formas "eu-pistêmicas" (Zoonen, 2012),

2 Termos como neocórtex e "cérebro reptiliano" denotam camadas cognitivas responsáveis pela articulação da memória incorporada (embodied), hábito e afetos, que são o alvo da economia comportamental e outras especialidades que subsidiam o design das arquiteturas das plataformas (Chun, 2016; Marres; Stark, 2020). cuja base são os indivíduos e suas respectivas trajetórias pessoais e experiências sensoriais. A eu-pistemologia (i-pistemology) opera na e pela desintermediação espaço-temporal, sendo sua forma típica o vídeo do evento que acaba de acontecer, que chega em primeira mão no smartphone e é imediatamente repassado adiante. Chun sugere que esses e outros efeitos de desintermediação acirram a "vontade de poder" dos usuários, incitando-os a atuarem como pequenos soberanos em seus feudos digitais nas mídias sociais e em outros ambientes dataficados do capitalismo de plataforma.

O diagnóstico de Chun converge com outros, referentes aos modos de individuação que os ambientes digitais contemporâneos propiciam (afford) (Boyd, 2011). Com base na filosofia da técnica de Gilbert Simondon, Lury e Day (2019) sugerem como a recursividade dos sistemas algorítmicos contemporâneos produz um modo de individuação fractal, que alia um hiperindividualismo a um hiper-relacionalismo. Assim, produzem-se perfis individuais que operam como elos estáveis necessários ao fluxo da economia de dados, ao mesmo tempo em que os "conteúdos" desses perfis não são fixos nem isolados, mas coemergem continuamente com outros perfis-em-rede num ritmo sempre intensivo. Esse modo de subjetivação paradoxal, que propiciou em 2018 o que chamei do "corpo digital do rei" (Cesarino, 2019), espelha a individuação-em-rede do neoliberalismo contemporâneo, notadamente o colapso de contexto entre indivíduo e empresa (ou pessoa incorporated) (Brown, 2015; Dardot; Laval, 2016).

Esses perfis, e as subjetividades off-line que eles ajudam a conformar, são performativos, emergindo a partir de uma lógica do marketing de influência cujo objetivo é produzir sujeitos influenciáveis, e não cidadãos autônomos e reflexivos (Mirowski, 2019). Essa lógica privilegia sistemas algorítmicos homofílicos, ou seja, que produzem conexão por meio da identidade, e não da diferença ou da aleatoriedade. Na interação com o mundo off-line, essa arquitetura acaba gerando subprodutos, 
como políticas de forte viés identitário (Pinto Neto, 2018), além do acentuado antagonismo amigo-inimigo observado nas múltiplas iterações da nova direita radical pelo mundo (Fielitz; Marcks, 2019).

Como argumentou Connolly (2021), a relação de causalidade entre infraestruturas de mídia e a política a elas associadas não é, e nem pode ser, direta ou linear. Os mesmos vieses algorítmicos que produzem os públicos-em-rede (Boyd, 2011) têm, na interação com usuários reais, levado a efeitos antiestruturais na forma de públicos refratados (Abdin, 2021) que operam também de forma sistêmica, porém fora do previsto pelas plataformas. Entre esses efeitos "uncanny" (Gray, Bounegru; Venturini, 2020) estariam o antagonismo de base cismogênica e a mímese inversa característicos dos populismos, conspiracionismos e negacionismos contemporâneos, cuja dinâmica se baseia no escalamento de oposições binárias e inversões antiestruturais do tipo redpilling ${ }^{3}$ (Cesarino, [2021?]; Leirner, 2020).

Este é um dos sentidos em que podemos pensar a irrupção dos populismos autoritários aspirantes a fascismo (Connolly, 2017) pelo prisma sistêmico ou infraestrutural. Uma das muitas dimensões da dialética a partir da qual essas forças emergem "nas ruínas do neoliberalismo" (Brown, 2019) converge com a tese antropológica de Louis Dumont (2000) sobre o totalitarismo como "englobamento do contráปี rio" da ideologia individualista moderna. Em i momentos de liminaridade e crise, a ênfase no ปิ individualismo e na identidade levaria à sua ¿ contrapartida antiestrutural: um coletivismo $\rightarrow$ radicalmente antagonístico. Como nos fascis¿. mos clássicos (Paxton, 2008), a irrupção deste ஓீ último em contextos de crise estaria desvenci$\overrightarrow{~ l i t h a d a ~ d e ~ u m a ~ b a s e ~ o r g a ̂ n i c a ~ c o e r e n t e, ~ s u b s u-~}$ mindo a seleção de conteúdos particulares à sua mecânica formal - nos termos heideggeria-

${ }^{3}$ Red pill refere-se à inversão figura-fundo propiciada pela pílula vermelha do filme Matrix, em que ao protagonista é oferecida a opção de acessar o mundo real, oculto por trás do mundo confortável, porém falso, produzido por máquinas que parasitam corpos humanos. nos de Laclau (2013), subsumindo "a política" no "político". Wendy Brown (2019) analisa em termos similares, e com base em Nietzsche, o tipo de niilismo que se intensifica no capitalismo neoliberal: não uma ausência de valores, mas sua desvinculação de uma base moral orgânica, levando a um transacionalismo e politização explícitos, como no trumpismo.

É sintomático da transversalidade da atual crise que Phillip Mirowski (2019) note um movimento semelhante, ao que Brown descreve para a mobilização neoconservadora dos "valores", da mobilização neoliberal dos "fatos”. À medida que a ciência passa a se orientar pela lógica do "mercado de ideias", a "verdade se desvencilha da argumentação" (p. 9) e se torna cada vez mais performativa. Com efeito, o modo como o estado de crise permanente desloca valores de uma base sociotécnica coerente e institui a busca por um acesso não mediado às fontes autênticas da "verdade" ecoa as formulações clássicas de Thomas Kuhn (2017) sobre o que ocorre com fatos em contextos de crise de paradigma. Os efeitos desse estado liminar parecem reverberar a dinâmica sistêmica que na antropologia se convencionou chamar de "involução": um estado contraditório de aumento intensivo da complexidade interna de um sistema apenas pela repetição de padrões formais, sem a produção de mudança ou criatividade reais (Geertz, 1969).

Ora, esta é precisamente a dinâmica neoliberal-digital descrita por Chun (2016), resultado de uma lógica performativa baseada na competição spenceriana e na segmentação homofílica. Numa lógica que guarda similaridades com o que se convencionou chamar de audit culture (Fisher, 2009; Strathern, 2000), os sujeitos precisam se autoperformar de forma cada vez mais intensiva apenas para conseguirem continuar existindo ou seu "vácuo" será ocupado por outro perfil empreendedor de si. O título do livro de Chun, updating to remain the same, ecoa essa dinâmica involutiva, em que mudança e complexificação "internos" tendem a repetir e intensificar padrões formais já ope- 
rativos no sistema, sem uma injeção de diversidade real que permitisse sua "evolução" na relação com o entorno (Luhmann, 2016). O fato de, com a plataformização, os sistemas algorítmicos operarem cada vez mais em "ambientes de testagem total” (Marres; Stark, 2020) que utilizam como input dados que eles próprios produzem é mais um indicativo da tendência involutiva que caracteriza tanto a economia de dados quanto o neoliberalismo contemporâneo (Peck; Theodore; Brenner, 2012). Contra a camisa de força dessa temporalidade involutiva, irromperiam os messianismos, punitivismos, populismos, conspiracionismos e outras forças políticas e espirituais que prometem repurificação e regeneração completa de um sistema não apenas compreendido, mas principalmente sentido (Connolly, 2021), como irreversivelmente corrompido e decadente.

Resta saber se esse estado liminar se encontra em vias de ser deslocado por um novo "paradigma” (Kuhn, 2017) emergente, ou se, pelo contrário, ficaremos presos a uma temporalidade paradoxal de crise permanente com a rotinização de muitos de seus "sintomas mórbidos" (Brown, 2020). Estaria a ancoragem da democracia contemporânea na infraestrutura cibernética das novas mídias levando a arranjos híbridos (Bickerton; Accetti, 2021; Davies, 2021) nos quais a temporalidade de crise e a gestão dos seus efeitos contraditórios se perenizam em novas recombinações? A transposição do populismo bolsonarista de uma gramática de ruptura radical a uma forma paradoxal de governo parece iluminar dimensões possíveis desses futuros incertos.

\section{TEMPORALIDADES BOLSONARIS-} TAS

\section{8: Ruptura e messianismo}

Diferentes perspectivas analíticas e empíricas já foram acionadas para lançar luz so- bre a "tempestade perfeita" que foi a vitória de Jair Bolsonaro em 2018 (Cesarino, 2019; Junge, 2019; Kalil et al., 2018; Leirner, 2020; Rocha, 2021). Trata-se de um fenômeno complexo com inúmeras dimensões relevantes, dentre as quais o papel das inovações comunicacionais assentadas na dependência cada vez maior dos eleitores brasileiros com relação a conteúdos circulados nas novas mídias. É sintomático que o icônico ano de 2013 também seja o marco da virada na venda de smartphones no Brasil. Como em muitos países que tiveram suas "primaveras" no vácuo da crise financeira de 2008, as potencialidades revolucionárias daquele momento único acabaram sendo, em larga medida, canalizadas eleitoralmente por uma nova direita ao mesmo tempo neoconservadora e anti-establishment (Brown, 2019).

Já foram bastante notadas e trabalhadas, em diversos países, as convergências entre affordances das mídias digitais contemporâneas e a dinâmica semiótica da política populista em noções como populismo algorítmico (Maly, 2019), métrico (Varis, 2020) ou digital (Cesarino, 2020; Silva, 2020). As novas tecnologias cibernéticas operam transversalmente às mídias tradicionais, permitindo conectar insatisfações e sentimentos anti-establishment outrora difusos e construir equivalência entre eles (Gerbaudo, 2018), corroendo assim a esfera pública liberal a partir de seu interior. O outro lado da construção da equivalência - no caso do bolsonarismo, entre os "patriotas" - é a construção da diferença em termos antagonísticos, isto é, de uma fronteira amigo-inimigo (Laclau, 2013). Estudos realizados a partir de diversos ângulos analíticos demonstraram a centralidade desta última para a vitória de Bolsonaro em 2018. Da anticorrupção ao antipetismo, do antipoliticamente correto ao antiglobalismo - inúmeros significantes flutuantes do inimigo foram microdirecionados para e a partir de segmentos diferentes como o lavajatismo, o conservadorismo religioso, os libertários ou neoliberais, os militares e polícias, entre outros (Cesarino, 2019, 2020; Junge, 2019; 
Kalil et al., 2018; Rocha, 2021).

Menos notado tem sido o papel da temporalidade de crise para a eficácia do populismo digital bolsonarista. A política no país já se encontrava em estado liminar desde ao menos 2013, aprofundado pelo lavajatismo e pelo movimento pró-impeachment que caracterizaram o interregno entre as eleições de 2014 e 2018. A partir desse pano de fundo preexistente, a campanha pró-Bolsonaro buscou aprofundar e, ao mesmo tempo, tomar as rédeas da metafísica da desordem vigente, principalmente por meios digitais. A esse respeito, cabe ressaltar que a nova direita bolsonarista, como outras (Maly, 2019), sempre foi explícita em sua intenção "metapolítica": os segmentos olavista e cristão evangélico em particular, mas também o militar e o ultraliberal, operam politicamente por vias oblíquas, quando não frontalmente opostas, aos mecanismos institucionais da política liberal-democrática (Leirner, 2020; Teitelbaum, 2020).

Eleições já, em si mesmas, são momentos liminares e, portanto, de perigo (Douglas, 2010), em que a abertura para a transição de poder faz entrever a lacuna entre o vazio do cargo e a fonte da soberania - no caso, o povo (Laclau, 2013). As eleições de 2018, ponto culminante de um longo período em si liminar, parecem ter acirrado esse seu caráter metapolítico. Marcante, naquele momento, foi a natureza messiânica assumida pela campanha Bolsonaro na esteira do ataque a faca sofrido $\overrightarrow{\mathcal{N}}$ pelo candidato no início de setembro. Muito i se discutiu sobre o real peso desse evento no ปิ resultado das eleições, mas não resta dúvida ¿े de que ele influenciou a própria dinâmica da $\rightarrow$ campanha durante o primeiro turno eleitoral, $\dot{2}$ uma vez que a decolagem de Bolsonaro nas ङึ pesquisas de intenção de voto se deu, paradoxalmente, na ausência da sua presença física da esfera pública.

Como argumentei anteriormente (Cesarino, 2019), as affordances fractais das novas mídias permitiram que um corpo digital de seguidores, os autodesignados "marqueteiros do Jair", assumisse a campanha em seu lugar. Os memes, vídeos, áudios, textos, canções e coreografias que inundaram o ecossistema digital performaram uma poderosa metaforização recíproca entre corpo do líder e corpo político do povo e da nação, propiciada pelos loops algorítmicos da internet participativa. Esta era simbolizada de forma icônica pelas versões digitais da camiseta que o candidato vestia no dia da facada, na qual ao slogan verde e amarelo "meu partido é o Brasil" se contrapunha o vermelho-sangue do ferimento desferido pelo inimigo. ${ }^{4}$ Naquele momento, o corpo do candidato penetrado pela faca - numa extraordinária coincidência, bem ao lado da palavra "Brasil" - tornou-se o país sangrado pela corrupção da "esquerda".

A facada tornou palpável a já corrente narrativa de perseguição do candidato pelo "sistema" e de que apenas sua vitória poderia impedir um iminente processo de destruição econômica e moral do país, encapsulado na ameaça da "venezuelização". Segundo o argumento benjaminiano de Coronil e Skurski (1991), eventos de violência em situações de crise "forçam os limites do permissível", fazendo que "biografia individual e história coletiva se unam momentaneamente, e história e corpo se tornem terrenos uns dos outros" (p. 289-290). A partir desse momento, pode-se argumentar que a campanha Bolsonaro adentrou o domínio metapolítico da temporalidade messiânica, prometendo um desenlace definitivo à metafísica da desordem vigente há anos. Enquanto um tipo de "iluminação profana” (Benjamin, 1996), este evento ajuda a compreender o poder das inversões não lineares avançadas por Bolsonaro, notadamente sua redenção do Regime Militar como período livre de corrupção e crime - ao menos, para os “cidadãos de bem" e verdadeiros patriotas. A promessa do líder antissistema de restaurar, em definitivo, a segurança e a ordem colocando o país "sob nova direção" manteve muitos

${ }^{4}$ No evento real não houve hemorragia externa, sendo o sangue editado digitalmente nas representações circuladas na época. 
seguidores afetivamente engajados na campanha como numa batalha de vida ou morte pelo futuro do país (Junge, 2019) - ou, como colocou Ernesto Araújo no seu blog da época (significativamente chamado "Metapolítica 17”), na sua "partida de futebol mais difícil". Como é característico de lideranças carismáticas de viés messiânico, as credenciais antissistema do candidato envolviam a performance de inversões estruturais, tais como nos casos de Bolsonaro e Trump, um linguajar e comportamento que batiam de frente com os protocolos e etiquetas do establishment político. Nos termos douglasianos de Luhrmann (2016), o elemento tabu aparece nessa situação como seu oposto, o sagrado: justamente pelo seu caráter antiestrutural, ele se coloca como único agente capaz de regenerar o sistema em bases totalmente novas (Douglas, 2010; Mazzarella, 2019).

A possibilidade dessas temporalidades e inversões não lineares era sustentada não apenas pelas affordances espaciais de ruptura com as mídias tradicionais e de desintermediação entre líder e seguidores (Gerbaudo, 2018), mas também pelas affordances temporais de crise permanente e "colapso de contexto" entre evento e narrativa inerentes à economia da atenção (Boyd, 2011; Chun, 2016). No WhatsApp e em sua ecologia de mídias mais ampla, notícias alarmistas em sites de "mídia alternativa”, áudios anônimos supostamente vazados por whistleblowers com acesso ao campo inimigo, narrativas conspiratórias elaboradas em detalhes vívidos em texto e vídeo retinham a atenção e o engajamento do "exército do Jair" no interior do ecossistema digital bolsonarista. $\mathrm{O}$ engajamento era periodicamente renovado por meio de pequenas tarefas e missões, como repassar conteúdos, atrair novos eleitores, desmonetizar canais e perfis de celebridades da esquerda, e ações off-line, como participação em manifestações de rua ou registro em vídeo das urnas eletrônicas no dia da eleição (Cesarino, 2020). Foi, em suma, uma campanha com um caráter literal de entretenimento. Os eleitores se sentiram, assim, não meros observa- dores, mas protagonistas da política e das decisões sobre o futuro do país - como há muito não acontecia.

Diante da grande intensividade do ritmo de engajamento e fluxo massivo de conteúdos nos grupos de WhatsApp e outras plataformas durante várias semanas, não me surpreendeu à época que a sensação geral, com o resultado eleitoral positivo, tenha sido não apenas de alegria mas de alívio. Era o horizonte do fim da temporalidade de crise: o Brasil estava finalmente entregue à vontade popular, representada de forma não mediada pela única liderança autêntica capaz de repurificar a política e o país. A maioria dos grupos de que participei durante a campanha logo se desfez, e os demais se reorganizaram no sentido de acompanhar as ações do novo governo e se manterem vigilantes contra ameaças renovadas por parte de velhos e novos inimigos. Para os que restaram naquele ecossistema, uma batalha crucial havia sido vencida, mas a guerra é sempre renovada.

\section{0: Rotinização e parasitismo}

Quando passou de candidato antissistema a governo, Jair Bolsonaro inicialmente manteve o espírito da sua campanha ao recusar coalizões com forças político-partidárias tradicionais, com exceção de nomes do Partido Democratas (DEM). Ao mesmo tempo, foi capaz de manter a lealdade de um núcleo duro significativo de apoiadores, enquanto os demais segmentos da sua base eleitoral foram mudando com o tempo. Ao longo do primeiro ano de governo, seu populismo antissistema parece ter menos se alterado do que se virado para dentro, no sentido de expurgar "inimigos internos" em desalinhamento com o líder (Leirner, 2020).

Com a irrupção da crise pandêmica, expurgos de grande repercussão levaram junto parte da base bolsonarista, como a saída do Ministro da Saúde Luiz Henrique Mandetta, e do Ministro da Justiça Sérgio Moro em abril de 
2020. O núcleo duro entendia este como um processo necessário de depuração: como sintetizou um meme que circulou à época, "o bolsonarismo não está diminuindo, mas se lapidando". A base agregada pelo populismo digital em 2018 foi assim gradativamente perdendo algumas de suas camadas mais "externas": o lavajatismo, parte da "antiga direita" e mesmo do partido pelo qual Bolsonaro se elegeu e do qual se retirou, o Partido Social Liberal (PSL). Em contrapartida, fortaleceu-se o núcleo duro militarista, evangélico, olavista e guedista em suma, a coalizão neoliberal-conservadora que espelha, justamente, a inflexão iliberal e autoritária do neoliberalismo contemporâneo discutida acima.

Este trabalho sugere que, embora tenha se acomodado ao establishment político a partir do pacto com o Centrão em meados de 2020, Bolsonaro manteve a temporalidade de crise permanente como fundamento do seu modo de governo. A dimensão messiânica de 2018 se perenizou, dando lugar a um estado de entropia epistêmica (Cesarino, 2021; Leirner, 2020) a partir do qual o presidente passou a atuar por meio da delegação ambígua a terceiros, sem se responsabilizar de fato pela gestão da crise pandêmica (Nobre, 2020). Tanto esse modus operandi quanto sua eficácia relativa, que tem impedido uma queda em popularidade grande o suficiente para sancionar o avanço das dezenas de pedidos de impeachment proสิ tocolados, estão em linha com a inflexão speni ceriana do neoliberalismo de viés conservador. ปี A doutrina neoliberal de base hayekiaN na visava deslegitimar e deslocar a agência do $\stackrel{\infty}{\rightarrow}$ Estado planejador que atua numa temporalida$\dot{2}$ de de médio prazo, substituindo-a pelo tempo लि pontuado do livre fluxo de agentes empreen-

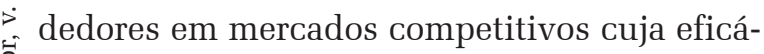
cia é emergente, e não deriva do tipo de previsibilidade em que se ancoram as políticas públicas (Dardot; Laval, 2016; Mirowski, 2019). É precisamente o que vemos na crise pandêmica no Brasil, que tem sido gerida de forma ad hoc por agentes públicos e privados sem um plane- jamento ou articulação centralizados no governo federal. Essa "experimentação no limiar da crise" ecoa o modo como o neoliberalismo se replica pela circulação de "políticas rápidas" emuladas localmente, sem um planejamento central (Peck; Theodore; Brenner, 2012). Na prática, isso significa que o presidente tem operado fundamentalmente por delegação: aos trabalhadores da saúde, aos militares, aos empresários, aos planos de saúde, aos médicos, aos indivíduos e famílias, e até aos inimigos, como o governador de São Paulo, João Dória. Ao mesmo tempo, segue atuando como agente desestabilizador, alegando estar sendo impedido de atuar pelos defensores do establishment, como governadores e prefeitos e o Supremo Tribunal Federal.

Marcos Nobre (2020) tem destacado esse caráter parasitário do governo Bolsonaro, que, como no neoliberalismo de modo mais amplo (Peck; Theodore; Brenner, 2012), se desenvolve numa relação paradoxal de dependência quanto ao próprio "sistema" a que alega se opor. Cabe lembrar que essa sempre foi uma característica do populismo bolsonarista, que vicejou ao longo dos anos parasitando tanto "amigos" - a simbologia do movimento pró-impeachment, a pauta do lavajatismo, dos evangélicos, da alt-right - quanto "inimigos" na sua relação de codependência cismogênica e de mímese inversa com a esquerda (Leirner, 2020; Cesarino e Silva [2022]). É característico dos populismos, especialmente aqueles "aspirantes a fascismo" (Connolly, 2017), serem vazios de conteúdo, uma vez que sua função é fundamentalmente performativa: a de construir o "povo" (Laclau, 2013). Como nos fascismos históricos (Paxton, 2008), seu conteúdo programático é renovado a partir dos loops entretidos com uma base formada por níveis mais ou menos fortes de adesão. As plataformas, que se baseiam na circulação de conteúdo gerado pelos próprios usuários, permitem que esse tipo de crowdsourcing ocorra de forma contínua, oferecendo métricas em tempo real para a gestão do ajuste entre líder e seguidores 
(Varis, 2020). Esse tipo de causalidade cibernética se alinha ao espaço-tempo não linear da internet contemporânea, favorecendo "formas de autoridade" que operam "numa lógica circular, e não teleológica, focada na performance de símbolos de poder ao invés de na entrega de resultados de políticas" (Davies, 2021, p. 9).

Assim, o presidente e seus aliados têm apostado menos na resolução da crise do que na manutenção da sua temporalidade e de um ambiente de desinformação que garanta sua sobrevivência política até as próximas eleições. Esse ambiente, cuja infraestrutura já se encontrava disponível nas mídias digitais (Gray; Bounegru; Venturini, 2020), é constantemente cultivado pelas próprias ações e declarações ambíguas do presidente, seus filhos e membros do seu governo. Como resultado, o período da crise pandêmica no Brasil tem sido marcado por uma sucessão de medidas ad hoc desvencilhadas de qualquer fundamento técnico-científico coerente (Casarões; Magalhães, 2021). No lugar de medidas coordenadas de isolamento social, por exemplo, Bolsonaro inventou um "isolamento vertical" que responsabilizasse as famílias pela (impossível) proteção dos seus membros mais vulneráveis, como idosos e pessoas com comorbidades. Mesmo suas referências ao chamado tratamento precoce sempre foram ambíguas. Ao mesmo tempo em que fazia propaganda das caixas de cloroquina diretamente aos seus seguidores, ele os direcionava a recorrerem a seus médicos para a decisão. Quando fez o exame de Covid-19, se recusou durante vários dias a mostrar o resultado. Após inicialmente negar ou minimizar a vacina, passou a alegar que sempre a buscou. Afirmou que seria o último brasileiro a ser vacinado e, por fim, decretou sigilo sobre a informação. E os exemplos se sucedem num padrão bastante previsível.

Esse pano de fundo de entropia ou alta equiprobabilidade permite o que chamei de hedging narrativo, em analogia com uma estratégia de gestão de risco no mercado financeiro que visa compensar potenciais perdas em um investimento apostando em outro ativo, que vai na direção oposta. Desse modo, o presidente pode até não arriscar o suficiente para ganhar muito, mas consegue manter um núcleo duro de apoiadores grande o suficiente para levá-lo ao segundo turno em 2022 (Nobre, 2020). Além disso, minimiza perdas entre este e outros segmentos da população ao manter uma margem de "negabilidade plausível" (Hodges, 2020) ampla o bastante para modular seu discurso a cada situação, evitando que causalidades e, portanto, responsabilização lhes sejam atribuídas de forma linear e inequívoca. Essa estratégia deixa em aberto, ainda, a possibilidade de reivindicar retrospectivamente crédito por medidas que não foram iniciadas ou implementadas por ele, como o auxílio emergencial e a Coronavac.

Com efeito, essa atuação por delegação a partir de um pano de fundo de crise permanente, que pode parecer paradoxal na perspectiva da política tradicional, tem se mostrado uma forma eficaz de defletir responsabilização pelos efeitos devastadores da pandemia. Mesmo com o acirramento das mortes, tanto de "CPF" quanto de "CNPJ", persiste um patamar significativo de brasileiros que parecem incapazes de traçar qualquer causalidade à figura do presidente. Entretanto, aqui como na campanha de 2018, essa eficácia não advém apenas dos vieses infraestruturais da plataformização e de uma boa estratégia comunicacional. Para funcionarem, táticas precisam ganhar tração no substrato social existente. E, nesse sentido, o presidente-influenciador parece de fato encontrar fortes ressonâncias (Connolly, 2021) com o conjunto de seus seguidores: assim como parte da população brasileira pareceu nunca ter demonstrado a expectativa de uma política pública bem planejada, universalmente justa e que lhes oferecesse condições para sustentar medidas de contenção do vírus, como o isolamento social (Cesarino e Silva [2022]), Bolsonaro nunca cogitou tal plano de combate à pandemia.

É nesse substrato que vimos convergir, novamente, a gramática spenceriana da luta 
pela existência e a gramática antagonística do populismo autoritário, ambas ancoradas na temporalidade de crise permanente. A pandemia da Covid-19 apenas acirrou e explicitou a dimensão de "estado de exceção" dessa configuração (Mbembe, 2018), especialmente evidente no idioma militarista tão característico do ex-capitão (Andrade, 2021). Com efeito, metáforas do espaço-tempo da guerra são utilizadas com frequência por Jair Bolsonaro, justificando, por exemplo, a utilização da cloroquina e outros remédios sem comprovação de eficácia contra a Covid-19 do mesmo modo que "na guerra do Pacífico, o soldado chegava sem sangue e não tinha outro para doar. O pessoal lá botou água do coco na veia. E deu certo. Imagina se fosse esperar uma comprovação científica” (09/04/2020, grifo nosso).

Navegando com destreza o colapso de contexto entre política e ciência que tem caracterizado a pandemia globalmente, o presidente brasileiro legitima e encoraja a extensão do estado de exceção e de sua temporalidade de crise à própria ciência (Campinas, 2020). No vácuo da inação governamental prolifera, principalmente por vias digitais, não apenas o populismo médico (Casarões; Magalhães, 2020) e a ciência patriótica (Fonseca; Ribeiro; Nascimento, 2020) de "cima pra baixo", mas todo um ecossistema de gestão da crise de "baixo pra cima”, centrado notadamente no chamado tratamento precoce. Proliferando "sob o radar" స్ (Abidin, 2021) do establishment científico por ì meio de infraestruturas digitais subterrâneas ฟิ propiciadas pela plataformização, esse ecosช sistema se compõe a partir da confluência es-


¿. de médicos a planos de saúde, de empresários लि a pacientes-especialistas, incluindo, no caso $\vec{i}$ brasileiro, algumas associações profissionais (Cesarino; Silva, [2021?]).Na ausência de uma política pública de cuidado, resta a lógica do livre mercado e suas formas de acolhimento, encapsuladas no "kit covid" enquanto "política rápida” (fast policy) neoliberal que alcança ampla circulação "a partir de modelos locais promissores que são plantados, escalonados e estilizados para emulação" (Peck; Theodore; Brenner, 2012, p. 279).

Há, finalmente, um outro sentido em que a abordagem do presidente para a pandemia encontra forte ressonância com a configuração neoliberal de viés autoritário, no qual crise permanente e estado de exceção se tornam a regra. Muitas de suas falas, como de que os brasileiros devem enfrentar o vírus sem "mimimi" ou "frescura", parecem buscar incutir na população disposições e afetos de estados de guerra (TV Brasil, 04/03/2021). Ou seja, os brasileiros, especialmente os mais vulneráveis, devem estar preparados para morrer, ou para verem seus familiares morrerem, se preciso for. A agência do vírus aparece aqui como um híbrido de força evolutiva, militarista e de mercado, que separa vencedores de perdedores numa luta pela existência cuja justiça é imanente e, em última instância, impenetrável. Em vez de um combate plasmado em intervenções amplas e planejadas, a luta contra o vírus torna-se, assim, uma guerrilha caótica, sem comando central, em que indivíduos e famílias devem desenvolver suas próprias estratégias de sobrevivência e, em última instância, a única agência capaz de mudar o rumo global das causalidades é a vontade inescrutável de Deus, energias positivas ou outras forças invisíveis que possam influenciar a imunidade e o processo de cura.

\section{CONSIDERAÇÕES CONCLUSIVAS}

Esse artigo sugeriu que temporalidades não lineares são uma dimensão importante para compreender as ressonâncias contemporâneas entre diferentes forças e poderes que têm sustentado a virada autoritária recente no Brasil e alhures. Neoliberalismo, plataformização, conservadorismo moral e religioso, punitivismo, táticas de guerra híbrida - todos operam segundo lógicas e dinâmicas que deslocam a temporalidade linear da moderni- 
zação que, como muitos notaram, vem se desestruturando com o ocaso do paradigma keynesiano-fordista. A crise financeira de 2008, que também marca o desenlace do processo de plataformização da internet, parece ter acelerado essa confluência, dando vazão dialética a derivas "iliberais" em muitas democracias pelo mundo. O Brasil de Bolsonaro durante a pandemia da Covid-19 parece encapsular, talvez como nenhum outro lugar, a culminação dessa encruzilhada histórica.

Temos, aqui, uma confluência talvez única entre a naturalização da desigualdade e da luta pela existência do neoliberalismo de base spenceriana e o antagonismo amigo-inimigo em que se ancoram os populismos da direita radical, o punitivismo, o militarismo, vertentes dispensacionalistas do cristianismo, e mesmo a estrutura básica de storytelling da indústria cultural de modo geral (Andrade, 2021; Comaroff; Comaroff, 2004; Connolly, 2017;). No contexto de crise aguda da pandemia, todos esses parecem se confundir numa metafísica vitalista na qual é esperado que apenas os mais aptos vençam ou sobrevivam - e não há nada que o Estado possa ou deva fazer para redistribuir a justiça biopolítica. Nas palavras do presidente, após lamentar a marca de 200 mil mortes: "temos que enfrentar isso daí", pois "a vida continua". ${ }^{5}$

A aceitação tácita da ideia de que é inadequado, e até antinatural, que um Estado redistributivo interfira na ordem espontânea (e desigual) das coisas e na liberdade soberana dos indivíduos e famílias parece advir, contudo, menos de uma ideologia coerente do que de uma resignação diante do fato de que "não tem dinheiro", "o Brasil não é Europa”, “a corrupção quebrou o Brasil” (Cesarino, [2021?]). Essas reações são espontâneas, porém ativamente alimentadas por um líder paradoxal que governa se recusando a governar; um soberano que se recusa a decidir. A resignação global

5 Disponível em: https://www.nexojornal.com.br/expresso/2021/04/07/As-respostas-de-Bolsonaro-diante-de-5-recordes-da-covid-em-2021. Acesso em: 4 nov. 2021. diante do realismo capitalista - de que não há alternativa - ganha tração, assim, ao se friccionar com a densidade histórica particular de uma formação pós-colonial que, como notamos inicialmente com Schwarz, sempre operou numa disjunção contraditória entre os princípios igualitários e universalistas da democracia liberal, e uma realidade social desigual e personalista. Os loops digitais pelos qual Bolsonaro vem coemergindo com seus seguidores fazem aflorar esse substrato histórico persistente e trancam o país num ciclo infernal de impotência e ressentimento, em que a única saída possível é do tipo messiânica: \#EuAutorizo.

No atual contexto neoliberal, em que o que era exceção - a crise - vira regra, essa disjunção, que parecia paradoxal do ponto de vista da temporalidade linear do progresso, parece encontrar uma estranha contemporaneidade. No ecossistema antilockdown e pró-tratamento precoce (Cesarino; Silva, [no prelo]), quando o senso comum fala em "salvar vidas", se refere menos ao planejamento tecnocrático de gestão biopolítica da pandemia do que a uma equação espontaneísta entre vida e trabalho precisamente, a promessa neoliberal (Dardot; Laval, 2016), mas agora redimensionada para um contexto de catástrofe. Como vem notando Brown (2019), é a lenta destruição neoliberal do "social" que vem tornando impensável, para as pessoas, intervenções redistributivas e planejadas mediadas por um Estado democraticamente responsivo. Vida é trabalho, pois a precarização neoliberal reduziu a vida à luta pela sobrevivência entre indivíduos e famílias (e agora, entre estes e o vírus). Voltamos novamente a Spencer. E na medida em que o neoliberalismo tende globalmente a essa deriva, o Brasil é lançado à vanguarda, pois sempre fomos, de certa forma, neoliberais-spencerianos. 


\section{REFERÊNCIAS}

ABIDIN, C. From "networked publics" to "refracted publics": a companion framework for researching "below the radar" studies. Social Media + Society, Thousand Oaks, p. 1-13, jan./mar. 2021.

ABREU, M. J. Before anything, above all: no decision. The Immanent Frame, [s. 1.], 9 Apr. 2019. Disponível em: https://tif.ssrc.org/2019/04/09/before-anything-above-allno-decision/. Acesso em: 23 out. 2021.

ANDRADE, D. Neoliberalismo e guerra ao inimigo interno: da Nova República à virada autoritária no Brasil. Caderno CRH, Salvador, v. 31, [2021?]. No prelo.

BENJAMIN, W. Obras escolhidas I: magia e técnica, arte e política. São Paulo: Brasiliense, 1996.

BICKERTON, C.; ACETTI, C. Technopopulism: the new logic of democratic politics. New York: Oxford University Press, 2021.

BOYD, D. Social network sites as networked publics: affordances, dynamics, and implications. In: PAPACHARISSI, Z. (org.). A networked self: identity, community, and culture on social network sites. New York: Routledge, 2011. p. 39-58.

BROWN, W. Nas ruínas do neoliberalismo: a ascensão da política antidemocrática no ocidente. São Paulo. Politéia, 2019.

Explaining our morbid political symptoms, interview by Daniel Denvir. Jacobin Magazine, New York, 12 jan. 2020. Disponível em: https://jacobinmag. com/2020/12/neoliberalism-wendy-brown-interviewnihilism-political-theory. Acesso em: 4 out. 2021.

CAMPINAS, M. Standards and urgency in times of pandemics: hydroxychloroquine as a pharmaceutical and political artefact. Somatosphere, [s. I.], 1 set. 2020. Disponível em: http://somatosphere.net/2020/standardsurgency-hydroxychloroquine-political-artefact.html/. Acesso em: 13 abr. 2020.

CARVALHO, L. Curto-circuito: o vírus e a volta do Estado. São Paulo: Todavia, 2020.

CASARÕES, G.; MAGALHÃES, D. The hydroxychloroquine alliance: how far-right leaders and alt-science preachers came together to promote a miracle drug. Revista de Administração Pública, Rio de Janeiro, v. 55, n. 1, p. 197214, 2021.

CESARINO, L. Colonialidade interna, cultura e mestiçagem: repensando o conceito de colonialismo interno na antropologia contemporânea. Ilha, Florianópolis, v. 9, $\overrightarrow{\text { ก }}$ n. 17, p. 73-105, 2017.

Identidade e representação no bolsonarismo: corpo ลิ digital do rei, bivalência conservadorismo-neoliberalismo O e pessoa fractal. Revista de Antropologia, São Paulo, v. 62, n. 3, p. 530-557, 2019.

. Como vencer uma eleicão sem sair de casa: $\rightarrow$ a ascensão do populismo digital no Brasil. Internet $\mathcal{E}$ $\rightarrow$ Sociedade, São Paulo, v. 1, n. 1, p. 92-120, 2020.

$\dot{1}$

. Pós-verdade e a crise do sistema de peritos: uma m explicação cibernética. Ilha, Florianópolis, v. 23, n. 1, $>$ p. 73-96, 2021.

के life of anti/corruption in Brazil. In: GOLDSTEIN, D.; T DRYBREAD, K. (org.). Corruption and illiberal politics in i the Trump Era. Abingdon: Routledge Press, [2021?]. No prelo.

CESARINO, L.; SILVA, V. H. Pandemic states of exception and the alt-science of "early treatment" for Covid-19 in Brazil. Latin American Perspectives, Thousand Oaks, [2021?]. No prelo.
CHUN, W. Updating to remain the same: habitual new media. Cambridge, MA: The MIT Press, 2016.

COMAROFF, J.; COMAROFF, J. Millennial capitalism: first thoughts on a second coming. Public Culture, Durham, v. 12 n. 2, p. 291-343, 2000.

Criminal obsessions, after foucault: postcoloniality, policing, and the metaphysics of disorder, Critical Inquiry, Chicago, v. 30, n. 4, p. 800-824, 2004.

Theory from the South: or, how Euro-America is evolving toward Africa. New York: Routledge, 2011.

CONNOLLY, W. Aspirational fascism: the struggle for multifaceted democracy under Trumpism. Minneapolis: University of Minnesota Press, 2017.

A máquina de ressonância evangélica-capitalista. In: CORREA, D.; PETERS, G. (ed.). Blog do Labemus. [S. l.], 5 abr. 2021. Disponível em: https://blogdolabemus. com/2021/04/05/a-maquina-de-ressonancia-evangelicacapitalista-por-william-e-connolly/. Acesso em: 4 out. 2021.

CORONIL, F.; SKURSKI, J. Dismembering and remembering the nation: the semantics of political violence in Venezuela. Comparative Studies in Society and History, Cambridge, v. 33, n. 2, p. 288-337, 1991.

DARDOT, P.; LAVAL, C. A nova razão do mundo: ensaio sobre a sociedade neoliberal. São Paulo: Boitempo, 2016.

DAVIES, W. The revenge of sovereignty on government? The release of neoliberal politics from economics post2008. Theory, Culture \& Society, Thousand Oaks, p. 1-24, 2021.

DOUGLAS, M. Pureza e perigo. São Paulo: Perspectiva, 2010.

DUMONT, L. Homo aequalis: gênese e plenitude da ideologia econômica. Bauru: EDUSC, 2000.

FERGUSON, J. Global shadows: Africa in the neoliberal world order. Durham: Duke University Press, 2006.

FIELITZ, M.; MARCKS, H. Digital fascism: challenges for the open society in times of social media. Berkeley: Berkeley Center for Right-Wing Studies, 2019.

FISHER, M. Realismo capitalista: é mais fácil imaginar o fim do mundo do que o fim do capitalismo? São Paulo: Autonomia Literária, 2020.

FONSECA, P.; RIBEIRO, B.; NASCIMENTO, L. Ignorance as power? Chloroquine and the co-production of truth in Brazil under Bolsonaro. Science and Democracy Network 2020 Annual Meeting, Cambridge, 2020.

FOUCAULT, M. The birth of biopolitics: lectures at the Collège de France, 1978-1979. London: Palgrave, 2008.

FRASER, N. Da redistribuição ao reconhecimento? Dilemas da justiça numa era "pós-socialista". Cadernos de Campo, São Paulo, v. 15, n. 14-15, p. 231-239, 1991.

GEERTZ, C. Agricultural involution: the processes of ecological change in Indonesia. Berkeley: University of California Press, 1969.

GERBAUDO, P. Social media and populism: an elective affinity? Media, Culture \& Society, Thousand Oaks, v. 8, n. 5, p. 745-753, 2018.

GRAY, J., BOUNEGRU, L.; VENTURINI, T. "Fake News" as infrastructural uncanny. New Media \& Society, Thousand Oaks, v. 22, n, 2, p. 317-341, 2020.

GUYER, J. Prophecy and the near future: thoughts on macroeconomic, evangelical, and punctuated time. American Ethnologist, Hoboken, v. 34, n. 3, p. 409-421, 2007.

HARRIS, T. The eyeball economy: how advertising co-opts independent thought. Big Think. Washington, DC, $10 \mathrm{abr}$. 
2017. Disponível em: https://bigthink.com/videos/tristanharris-the-attention-economy-a-race-to-the-bottom-of-thebrain-stem. Acesso em: 4 out. 2021.

HODGES, A. Plausible deniability. In: MCINTOSH, J.; MENDOZA-DENTON, N. (org.). Language in the Trump Era: scandals and emergencies. Cambridge: Cambridge University Press, 2020. p. 137-149.

JUNGE, B. "Our Brazil has become a mess": nostalgic narratives of disorder and disinterest as a "once $\square$ rising poor' family from Recife, Brazil, anticipates the 2018 elections. The Journal of Latin America and Caribbean Anthropology, Hoboken, v. 24, n. 4, p. 914-931, 2019.

KALIL, I. et al. Quem são e no que acreditam os eleitores de Jair Bolsonaro. São Paulo: Fesp-SP, 2018.

KLEIN, N. A doutrina do choque: a ascensão do capitalismo do desastre. Rio de Janeiro: Nova Fronteira, 2008.

KUHN, T. A estrutura das revoluções científicas. São Paulo: Perspectiva, 2017.

LACLAU, E. A razão populista. São Paulo: Três Estrelas, 2013.

LEIRNER, P. O Brasil no espectro de uma guerra híbrida militares, operações psicológicas e política em uma perspectiva etnográfica. São Paulo: Alameda Editorial, 2020

LUHMANN, N. Sistemas sociais: esboço de uma teoria geral. Petrópolis: Vozes, 2016

LUHRMANN, T. The paradox of Donald Trump's appeal. Sapiens, New York, 29 jul. 2016. Disponível em: https:// www.sapiens.org/culture/mary-douglas-donald-trump/. Acesso em: 4 out. 2021

LURY, C.; DAY, S. Algorithmic personalization as a mode of individuation. Theory, Culture \& Society, Thousand Oaks, v. 36, n. 2, p. 17-37, 2019.

MALY, I. new right metapolitics and the algorithmic activism of Schild \& Vrienden. Social Media + Society, Thousand Oaks, v. 5, n. 2, p. 1-15, 2019.

MARRES, N.; STARK, D. Put to the test: for a new sociology of testing. The British Journal of Sociology, Hoboken, v. 71 n. 3 , p. $423-443,2020$.

MBEMBE, A. Necropolítica. São Paulo: N-1 Edições, 2018.

MIROWSKI, P. Hell is truth seen too late. Boundary 2, Durham, v. 46, n. 1, p. 1-53, 2019.

NOBRE, M. The global uprising of populist conservatism and the case of Brazil. In: GIESEN, K. (org.). Ideologies in world politics. New York: Springer, 2020. p. 157-178.
PAXTON, R. A anatomia do fascismo. São Paulo: Paz \& Terra, 2008.

PECK, J.; THEODORE, N.; BRENNER, N. Neoliberalism resurgent? Market rule after the great recession. South Atlantic Quarterly, Durham, v. 111, n. 2, p. 265-288, 2012.

PINTO NETO, M. O extrativismo identitário em Black Mirror. In: CAVA, B; CORREAA, M. (org.). Pensar a Netflix: séries de pop filosofia política. Belo Horizonte: D’Plácido, 2018. p. 99-112.

PLEWE, D.; SLOBODIAN, Q.; MIROWSKI, P. (org.). Nine lives of neoliberalism. New York: Verso Books, 2020

ROCHA, J. C. Guerra cultural e retórica do ódio: crônicas de um Brasil pós-político. Goiânia: Editora e Livraria Caminhos, 2021.

SENNETT, R. A corrosão do caráter: consequências pessoais do trabalho no novo capitalismo. Rio de Janeiro: Record, 1999.

SCHWARZ, R. As ideias fora do lugar. São Paulo: Companhia das Letras, 2014.

SILVA. D. (org.). Mecanismos digitais e semióticos dos populismos contemporâneos. Trabalhos em Linguística Aplicada, Campinas, v. 59, n. 2, p. 1047-1050, 2020.

STRATHERN, S. Audit cultures: anthropological studies in accountability, ethics, and the academy. London: Routledge, 2000

TEITELBAUM, B. Guerra pela eternidade: o retorno do tradicionalismo e a ascensão da direita populista. Campinas: Editora da Unicamp, 2020.

TSING, A. Friction: an ethnography of global connection. Princeton: Princeton University Press, 2005.

VARIS, P. Trump tweets the truth: metric populism and media conspiracy. Trabalhos em Linguística Aplicada, Campinas, v. 59, n. 1, p. 428-443, 2020.

WACQUANT, L. Punishing the poor: the neoliberal government of social insecurity. Durham: Duke University Press Books, 2009.

WAISBORD, S. The elective affinity between post-truth communication and populist politics. Communication Research and Practice, Abingdon, v. 4, n. 1, p. 17-34, 2018.

ZOONEN, L. I-pistemology: changing truth claims in popular and political culture. European Journal of Communication, Thousand Oaks,v, 27, n. 1, p. 56-67, 2012. 
PUTTING IDEAS BACK IN PLACE?

non-linear temporalities in Brazil's authoritarian neoliberalism and its digital infrastructure

\section{Letícia Cesarino}

The article approaches how the populistauthoritarian inflection of global neoliberalism has gained traction in Brazil through friction with its post-colonial historical condition, marked by a disjunction between egalitarian, universalist liberal ideals and an unequal, particularistic social reality. I will pay special attention to infrastructural convergences between neoliberalization and platformization, which, by creating a paradoxical temporality of permanent crisis, resonate with "forces and powers" that also operate non-linearly according to a metaphysics of disorder, such as the various forms of nostalgia, millenarianism, and traditionalism that follow the rise of the radical right throughout the world. I developed this argument focusing on two moments of Bolsonarism: the populist messianism during the 2018 elections, and its paradoxical routinization as a parasitic government operating in a temporality of exception, during the Covid-19 pandemic. This article suggestes that, in the face of the illiberal drift of contemporary neoliberalism, Bolsonarism propels Brazil into an avant-garde, putting ideas "back in place".

Keywords: Neoliberalism. Platformization. Brazil. Bolsonarism. Crisis.
LES IDÉES SONT-ELLES DE NOUVEAU EN PLACE? temporalités non-linéaires dans le néolibéralisme autoritaire brésilien et de sa infrastructure numérique

\section{Letícia Cesarino}

L'article traite de la manière dont l'inflexion populiste-autoritaire du néolibéralisme mondial a gagné du terrain au Brésil par friction avec sa densité historique post-coloniale, marquée par la disjonction entre des idéaux égalitaires et universalistes libéraux et une réalité sociale inégalitaire et particulariste. Une attention particulière sera accordée à la convergence infrastructurelle entre néolibéralisation et plateformisation, qui, en consolidant une temporalité paradoxale de crise permanente (Chun, 2016), fait place à des résonances avec des "forces et des pouvoirs" qui opèrent aussi de manière non-linéaire selon une métaphysique du désordre, comme les diverses formes de nostalgie, millénarisme et traditionalisme qui accompagnent la montée de la droite radicale dans le monde. Je développe l'argument à partir de deux moments du bolsonarisme: le messianisme populiste lors des élections de 2018 et, pendant la pandémie de covid-19, sa routinisation paradoxale en tant que gouvernement parasite qui opère dans une temporalité d'exception. Il est suggéré que, face à la dérive illibérale du néolibéralisme contemporain, le bolsonarisme lance le Brésil sur la avant garde, donc en remettant les idées "en place".

Mots-CLÉs: Néolibéralisme. Plateformisation. Brésil. Bolonarisme. Crise. Federal de Santa Catarina. Desenvolve pesquisas na área de antropologia digital, neoliberalismo, cibernética e teorias de sistemas. Suas mais recentes publicações são: Pós-verdade e a crise do sistema de peritos: uma explicação cibernética. Ilha Revista de Antropologia 23, $\mathrm{n}^{\mathrm{O}} 1$ (24 de fevereiro de 2021), p. 73-96; Antropologia digital não é etnografia. Civitas - Revista de Ciências Sociais 21, nº 2 (24 de agosto de 2021), p. 304-15. 